\title{
Expression of CXCL10 is associated with response to radiotherapy and overall survival in squamous cell carcinoma of the tongue
}

\author{
Matilda Rentoft • Philip John Coates • Lotta Loljung • \\ Torben Wilms • Göran Laurell • Karin Nylander
}

Received: 13 November 2013 / Accepted: 12 December 2013 /Published online: 7 January 2014

(C) The Author(s) 2014. This article is published with open access at Springerlink.com

\begin{abstract}
Five-year survival for patients with oral cancer has been disappointingly stable during the last decades, creating a demand for new biomarkers and treatment targets. Lately, much focus has been set on immunomodulation as a possible treatment or an adjuvant increasing sensitivity to conventional treatments. The objective of this study was to evaluate the prognostic importance of response to radiotherapy in tongue carcinoma patients as well as the expression of the CXCchemokines in correlation to radiation response in the same group of tumours. Thirty-eight patients with tongue carcinoma that had received radiotherapy followed by surgery were included. The prognostic impact of pathological response to
\end{abstract}

\footnotetext{
M. Rentoft $(\bowtie)$

Department of Chemistry, Umeå University, 90185 Umeå, Sweden

e-mail: matilda.rentoft@chem.umu.se

P. J. Coates

Tayside Tissue Bank, Medical Research Institute, Ninewells Hospital and Medical School, University of Dundee, Dundee, UK

e-mail: p.j.coates@dundee.ac.uk
}

M. Rentoft $\cdot$ L. Loljung $\cdot$ G. Laurell $\cdot$ K. Nylander Department of Medical Biosciences/Pathology, Umeå University, Building 6M, 2nd Floor, 90185 Umeå, Sweden

L. Loljung

e-mail: lotta.loljung@hotmail.com

G. Laurell

e-mail: goran.laurell@surgsci.uu.se

K. Nylander

e-mail: karin.nylander@medbio.umu.se

T. Wilms

Department of Clinical Sciences/Otorhinolaryngology,

Umeå University Hospital, 90187 Umeå, Sweden

e-mail: torben.wilms@ent.umu.se

G. Laurell

Department of Surgical Science/ENT, Uppsala University Hospital, 75185 Uppsala, Sweden radiotherapy, $\mathrm{N}$-status, T-stage, age and gender was evaluated using Cox's regression models, Kaplan-Meier survival curves and chi-square test. The expression of $23 \mathrm{CXC}$-chemokine ligands and their receptors were evaluated in all patients using microarray and qPCR and correlated with response to treatment using logistic regression. Pathological response to radiotherapy was independently associated to overall survival with a 2-year survival probability of $81 \%$ for patients showing a complete pathological response, while patients with a noncomplete response only had a probability of $42 \%$ to survive for 2 years $(p=0.016)$. The expression of one CXCchemokine, CXCL10, was significantly associated with response to radiotherapy and the group of patients with the highest CXCL10 expression responded, especially poorly ( $p$ $=0.01$ ). CXCL10 is a potential marker for response to radiotherapy and overall survival in patients with squamous cell carcinoma of the tongue.

Keywords Oral cancer · Tongue $\cdot$ Chemokines $\cdot$ CXCL10 $~$ Radiotherapy $\cdot$ Prognosis

\section{Introduction}

Squamous cell carcinoma (SCC) in the oral cavity is one of the ten most common malignancies worldwide, with the tongue being the most tumour prone sub-site. The relatively low 5 year survival, of around $50 \%$, has remained disappointingly stable over the last few decades in spite of improvements in the main treatments of surgery and radiotherapy [1-3]. This has evoked a rising interest in identifying biomarkers that are able to predict prognosis and response to treatment [2]. Today the most informative marker is node status, $\mathrm{N}$-status, where cervical lymph node involvement drastically worsens the prognosis $[4,5]$. A complicating factor is the fairly high rate 
of occult cervical nodal metastasis, which is especially frequent in tumours of the tongue $(\sim 30 \%)$ [3].

Several factors are known to influence response to radiotherapy in head and neck cancer patients, including tumour characteristics (e.g. location, volume and tumour stage), patient characteristics (e.g. smoking status) and biological factors (e.g. hypoxia and expression of DNA repair genes) [6-9]. The potential of the natural immune response for improving response to conventional treatments has recently been in focus [10-12]. The goal is to enhance the anti-tumoural specific response, which can be achieved either by nonspecific or specific stimulation of the immune system. The immune response towards tumours is, however, a complex process, involving both pro- and anti-tumour components and research on the interaction between tumours and the microenvironment is still fairly young.

Chemokines are small secreted immune modulators representing a large family of proteins that were initially characterized as attractants of leucocytes. They signal through G-protein-coupled (chemokine) receptors and are divided into four subgroups ( $\mathrm{CC}, \mathrm{CXC}, \mathrm{CX} 3 \mathrm{C}$ and $\mathrm{C}$ ), depending on structure, with $\mathrm{CC}$ and $\mathrm{CXC}$ representing the major classes. CXC-chemokines were initially closely related to angiogenesis and are further divided into angiogenic and angiostatic but are also reported to be important for cell survival and metastasis [12]. Several CXC-chemokine ligands activate more than one receptor, and the majority of the receptors bind several CXC-ligands. They are induced by inflammatory cytokines, growth factors and pathogenic stimuli and are produced and secreted by many different cell types including tumour cells and tumour-infiltrating immune cells.

In addition to their importance for tumour survival, metastasis and angiogenesis, chemokines have recently been implicated in treatment response [12]. A number of studies have shown a considerable effect of radiation on chemokine expression, and there are indications for a role for chemokines in resistance to chemo- and radiotherapy [13-16]. Chemokines are interesting molecular targets due to their properties as natural immune modulators, and monoclonal antibodies against chemokine receptors have been used in experimental settings to inhibit growth and spread of malignant tumours $[17,18]$. The role and expression of many chemokines are not yet well established in oral cancer, but a study mapping the expression of 24 chemokine ligands and receptors in a number of SCC head and neck cell lines before and after radiation was recently published. This study showed large variation in chemokine receptor and ligand expression, and further evaluation of chemokines as biomarkers for radiation response was suggested to be of value [19].

The aim of this study was to summarize the expression of CXC-chemokines in tongue tumours and investigate the relationship to radiation response. Additionally, the association between radiation response and 5 year survival in tongue tumour patients was assessed, as response to preoperative treatment has prognostic value in some other solid tumours, including tonsillar carcinoma [20-22]. Results showed a strong association between radiation response and overall survival for tongue tumour patients and identified CXCL10 as a candidate chemokine for predicting radiation response.

\section{Patients and methods}

Patients

Thirty-eight patients for which response to radiotherapy could be evaluated were identified from a previous study on stromal inflammation and tongue cancer [23]. These patients had received and completed preoperative radiotherapy, and surgery and pathological evaluation of the response to radiotherapy were performed on surgical specimens at the ENT Clinic, Norrlands University Hospital. The pathological response was judged as complete (cPR) if no viable cancer cells could be detected and as incomplete (non-cPR) if viable cancer cells were detected. Patients were classified as young if diagnosed before 40 years of age and classified as old if over 40 years at diagnosis, in accordance with the literature [24-29]. The study was approved by the local ethics committee (dnr 01-210; dnr 08-003M)

\section{Array data}

Microarray data from samples taken at diagnosis for all 38 patients had previously been made publically available at gene expression omnibus (GEO) (accession number GSE34115), and data for 16 of the 17 CXC-chemokine ligands and all 7 chemokine receptors were extracted [30]. Even though data for 24 more tongue tumours were available, we focused on the 38 patients for which pathological response to radiotherapy could be evaluated. The chemokine ligand CXCL15 was not available on the microarray chip and therefore not included in the study. Array data for normal tongue tissue from 16 controls also included in the above study was used for comparison.

\section{qPCR data}

Expression of the chemokine ligand CXCL10 was evaluated using qPCR in all samples. Relative quantities were calculated using the $\Delta$ CT method. The gene TUBA6, previously demonstrated to be stably expressed in oral FFPE tissue, was used as reference gene [31, 32]. cDNA reactions were performed using RevertAid H minus first strand cDNA kit (Fermentas Gmbh, Leon-Rot, Germany) with 200 ng of RNA. For the PCR reactions, the quanti tect primer assay was used for CXCL10 and inhouse designed primers for TUBA6 together with the quanti tect SYBR green assay (Qiagen Gmbh, Hamburg, Germany) [32]. 
Statistical analysis

Correlations between the 2-year survival and age, gender, Tstage, $\mathrm{N}$-status and pathological response to radiotherapy were investigated by chi-square tests, and Cox's regression models were used to assess their prognostic value. Survival curves were drawn using the Kaplan-Meier method, and the log rank test was used to assess the survival difference between groups.

Fold changes and significances (tumour vs control) for the CXC-chemokines were calculated using array data. A value above or below the mean expression of controls plus/minus two standard deviations (mean control $\pm 2 * \mathrm{SD}$ ) was used as a cut-off to decide how many tumours had increased/decreased expression of the separate CXC-chemokines. Array data for all CXC-chemokines and qPCR data for CXCL10 were used to correlate expression levels to pathological response to radiotherapy using logistic regression, both in a univariate analysis and a multivariate model correcting for gender, age, size of tumour and nodal status. Expression of CXCL10 was additionally categorized into three similar sized groups, low ( $n$ $=13)$, medium $(n=12)$ and high expression $(n=13)$, to further evaluate its relationship to pathological response to radiotherapy. The significance level was set to $p<0.05$, and all analysis were performed using SPSS software version 19.0 (SPSS Inc., Chicago, IL, USA)

\section{Results}

\section{Clinical data}

Clinical data is summarized in Table 1. The male to female ratio was $1.2: 1$, and most patients presented with a $\mathrm{T} 1$ or $\mathrm{T} 2$ tumour (76\%). The age span was 19-81 years, with a mean age of 50 years, which is slightly lower than the typical patient group. This could partially be caused by a larger proportion of the older patients being judged as unfit for surgery in contrast to more of the younger patients completing both radiotherapy and surgery. Pathological response to radiotherapy was evaluated in surgical samples from all 38 patients; 26 patients showed complete response (cPR) and 12 did not (non-cPR). For three patients with non-cPR, the tumour was not radically removed at surgery. One of these patients went through extended surgery, showing tumour-free resection margins, and two were treated with cytostatics. All patients had been followed for at least 2 years or until death.

Importance of complete response to preoperative radiotherapy for overall survival

Univariate survival analysis by Cox's regression of the variables pathological response to radiotherapy, gender, age, Tstage or N-status identified pathological response to treatment
Table 1 Summary of patients data

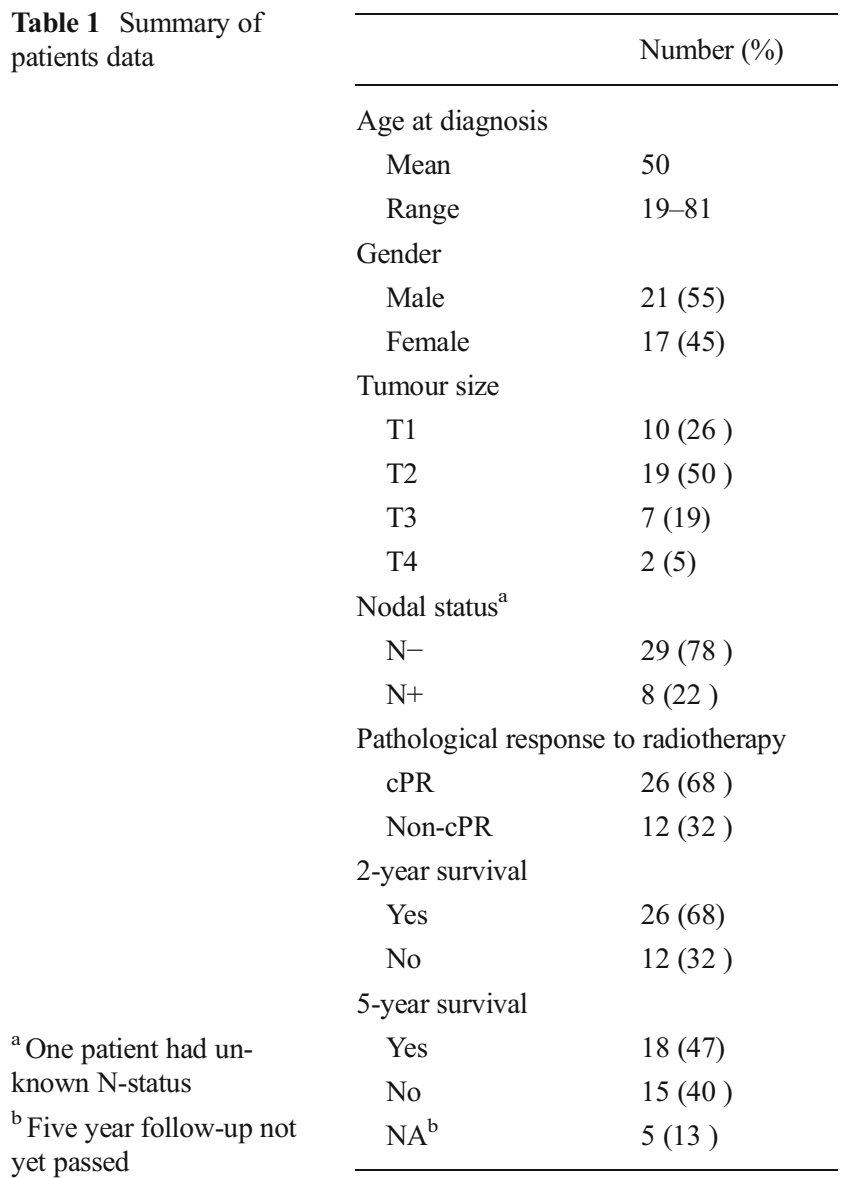

\begin{tabular}{|c|c|c|}
\hline & \multicolumn{2}{|c|}{ Age at diagnosis } \\
\hline & Mean & 50 \\
\hline & Range & $19-81$ \\
\hline & \multicolumn{2}{|l|}{ Gender } \\
\hline & Male & $21(55)$ \\
\hline & Female & $17(45)$ \\
\hline & \multicolumn{2}{|l|}{ Tumour size } \\
\hline & $\mathrm{T} 1$ & $10(26)$ \\
\hline & $\mathrm{T} 2$ & $19(50)$ \\
\hline & $\mathrm{T} 3$ & $7(19)$ \\
\hline & $\mathrm{T} 4$ & $2(5)$ \\
\hline & \multicolumn{2}{|l|}{ Nodal status ${ }^{\mathrm{a}}$} \\
\hline & $\mathrm{N}-$ & $29(78)$ \\
\hline & $\mathrm{N}+$ & $8(22)$ \\
\hline & \multicolumn{2}{|c|}{ Pathological response to radiotherapy } \\
\hline & cPR & $26(68)$ \\
\hline & Non-cPR & $12(32)$ \\
\hline & \multicolumn{2}{|c|}{ 2-year survival } \\
\hline & Yes & $26(68)$ \\
\hline & No & $12(32)$ \\
\hline & \multicolumn{2}{|c|}{ 5-year survival } \\
\hline${ }^{a}$ One patient had un- & Yes & $18(47)$ \\
\hline known N-status & No & $15(40)$ \\
\hline${ }^{\mathrm{b}}$ Five year follow-up not & $\mathrm{NA}^{\mathrm{b}}$ & $5(13)$ \\
\hline
\end{tabular}

as the only variable significantly correlating to overall survival (hazard ratio (HR) $95 \%$ confidence interval (CI), 6.0 (2.116.9), $p=0.001)$. Multivariate analysis further demonstrate that pathological response to radiotherapy was an independently unfavourable prognostic factor (HR 95 \% CI, 5.3 (1.716.9), $p=0.005)$. Chi-square test showed that a cPR was already important for the 2-year survival $(p=0.016)$, with $81 \%$ probability of surviving 2 years when having a complete response to radiotherapy as compared to $42 \%$ for patients with non-cPR. Survival curves for patients with a non-cPR as compared to patients with cPR can be found in Fig. 1a and it illustrates a significantly poorer overall survival for patients with a non-cPR $(p<0.001, \log$ rank test). After removing the three patients for whom initial surgery did not radically remove the tumour from the analysis, results remain significant $(p=0.002, \log$ rank test $)$.

Expression of the CXC family of chemokines and their receptors in tongue tumours

RNA from all 38 patients and probes for detection of all but one of the $24 \mathrm{CXC}$-chemokine ligands and receptors were 


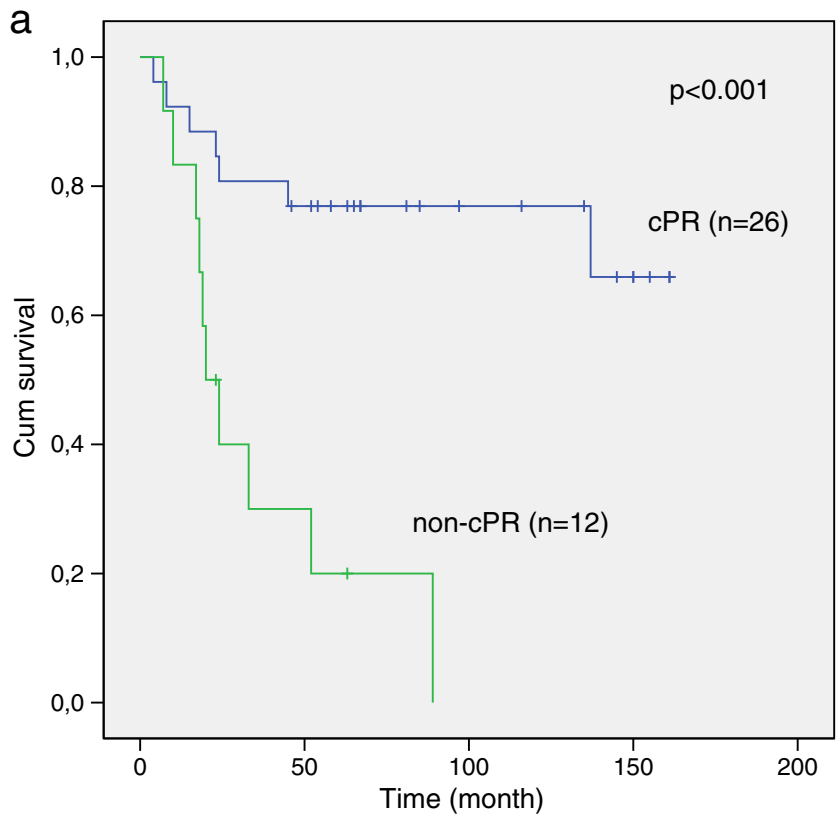

b

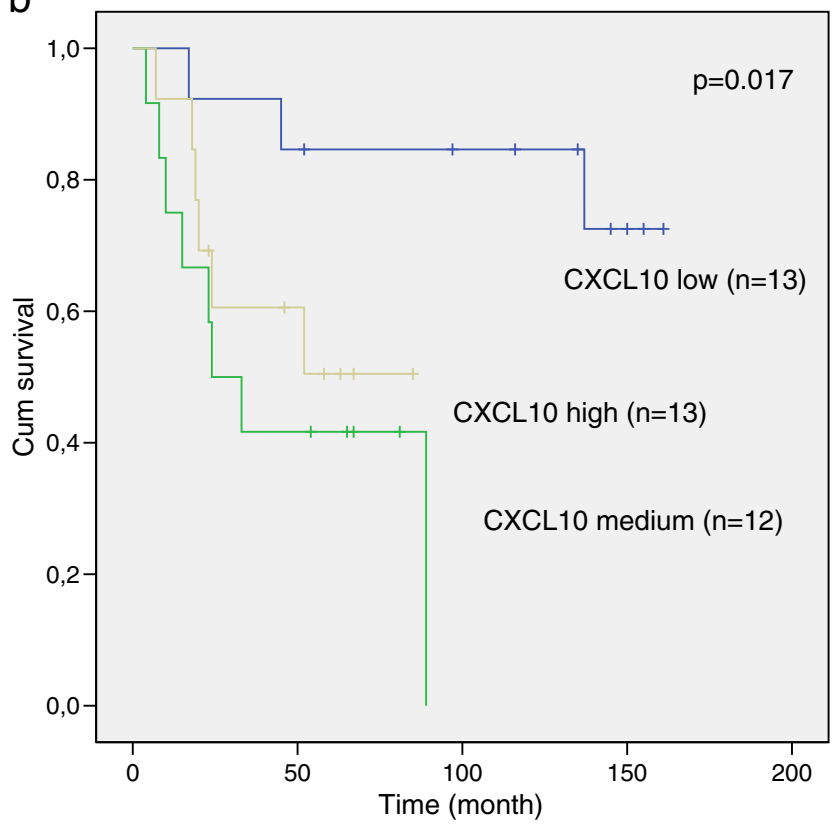

Fig. 1 Kaplan-Meier survival curve showing a the relationship between pathological response to radiotherapy (cPR vs non-cPR) and overall survival. b The relationship between grouped CXCL10 expression (low, medium, high) and overall survival censoring of patients is shown as vertical lines

included in a previously published microarray study made public on GEO [30], and their expression in tongue tumours as compared to controls is summarized in Fig. 2. Five of the CXC-chemokines (CXCL3, 4, 9 and 16 and CXCR4) had a detection $p$ value above 0.05 (caused by low signal or low stringency), and data for these should thus be interpreted with care. Eight CXC-chemokine ligands were significantly upregulated (CXCL1, 2, 5, 6, 8, 10, 11, 13), and none were significantly down-regulated. Of the receptors, three were significantly up-regulated (CXCR3, 5, 6) and one (CXCR1) significantly down-regulated. CXCL10 had the highest fold change with an average increase of 16-fold. For some chemokines, a changed expression ( $>$ mean control $\pm 2 * \mathrm{SD}$ ) could be seen in almost all patients, while other chemokines were only increased or decreased in a subgroup of patients summarized in Table 2.

Association between the expression of CXCL10 and response to radiotherapy

Using continuous array data and logistic regression to investigate the association between CXC-chemokine ligand and receptor expression in response to radiotherapy, one chemokine, CXCL10, was found to be significant $(p=0.03)$, with higher levels resulting in a poorer response to radiotherapy.

Because of the somewhat noisy nature of microarray data, CXCL10 levels were analysed using qPCR to obtain more accurate expression values before further evaluating the relationship with radiotherapy response. The correlation between the two methods (qPCR and microarray) was good ( $R=0.76$ ). In a multivariate logistic regression model, correcting for gender, age, size of tumour and nodal-status, CXCL10 expression was again significantly associated with response to radiation therapy $(p=0.05)$. Categorising samples into three equal groups according to CXCL10 expression (low, medium, high) showed that patients with the highest expression of CXCL10 had significantly poorer pathological response to radiotherapy compared to patients expressing the lowest levels $(p=0.01)$ (Table 3$)$. Survival analysis of patients according to the categorised CXCL10 expressions showed significantly better survival in the group with the lowest expression of CXCL10 ( $p=0.017$, log rank test) (Fig. 1b).

\section{Discussion}

In spite of the easily accessible location of tumours in the oral cavity, both from a diagnostic and a therapeutic point of view, survival is fairly low and patients die from metastatic disease, loco-regional recurrence and second primary tumours. In this study, we found that complete response to preoperative radiation is important for survival in tongue cancer patients and that CXCL10 expression could indicate resistance to radiotherapy.

Response to preoperative treatment has previously been shown to be a strong prognostic marker for a number of cancers. In a large study on 167 tonsillar carcinomas, Friesland and co-workers found that the probability of surviving 5 years when displaying complete response to radiotherapy was $79 \%$, while it was only $9 \%$ for patients showing incomplete response $(p=<0.0001)$ [21]. Similar results were achieved when looking at cervical cancer stage Ib and IIa and 


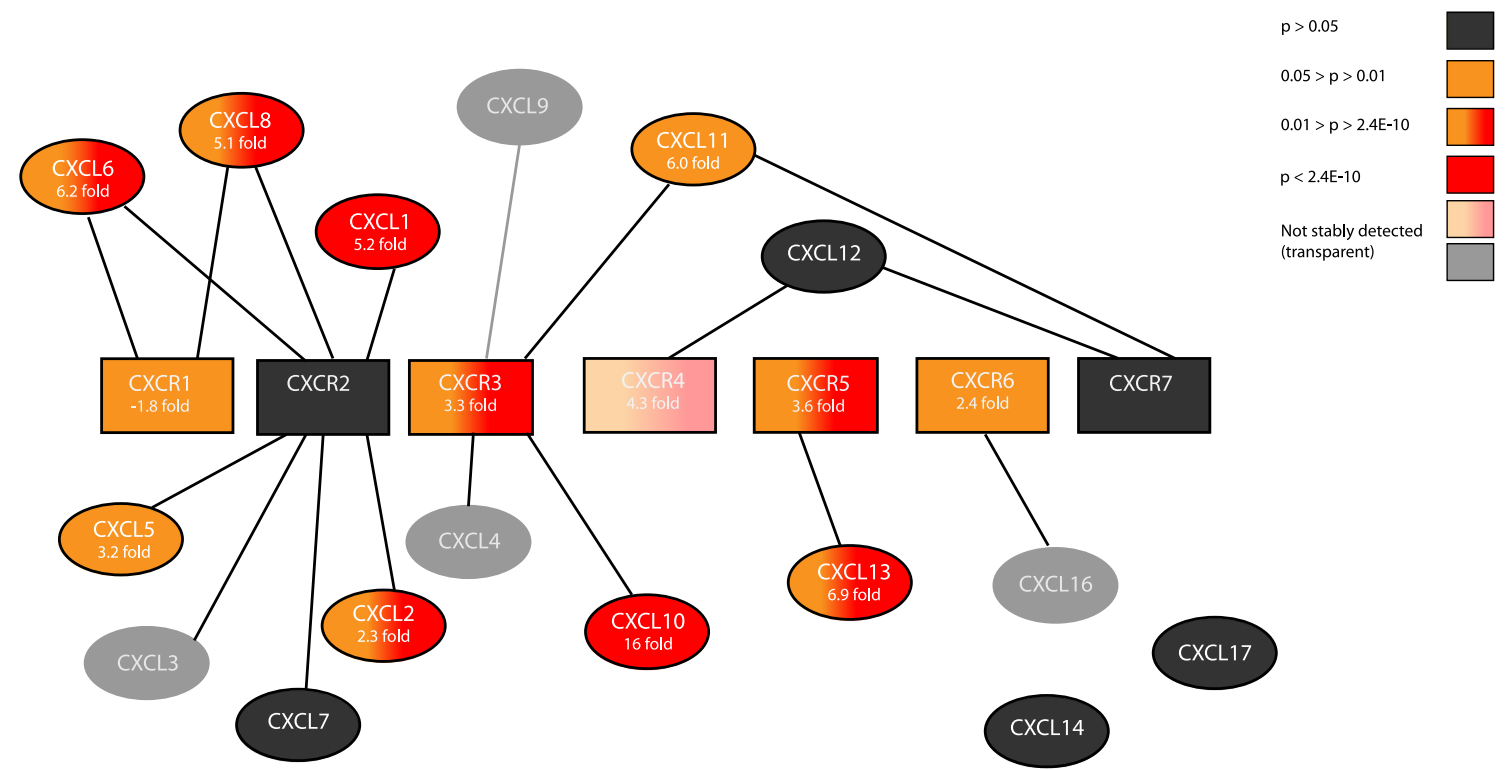

Fig 2 Summary of microarray expression data for all CXC-chemokine ligands (oval) and receptors (squares), except CXCL15, in tongue tumours compared to normal controls. Colour indicates significance as

preoperative radiotherapy (5-year survival $\mathrm{cPR}=95 \%$ and non-cPR $=46 \%, p<0.0001)$ as well as breast cancer and preoperative chemotherapy (5-year survival $\mathrm{cPR}=88 \%$ and non-cPR $=77 \%, p<0.033)[20,22]$. In our cohort of tongue tumour patients, a cPR after preoperative radiotherapy resulted in a 2-year survival of $81 \%$, while patients with a non-cPR only had $42 \%$ probability of surviving 2 years $(p=0.016)$, confirming the importance of radiotherapy response also in these patients.

$\mathrm{N}$-status is a well-known predictor of prognosis, and the fact that no significance was obtained in this study is probably partially due to the small number of $\mathrm{N}+$ patients $(n=8)$. The high number of expected occult metastasis in tongue tumours $(\sim 30 \%)$ also decreases the sensitivity of the analysis [3]. The survival of young tongue cancer patients is a much debated

Table 2 Percentage of samples with increased/ decreased expression of the significant CXC-ligands and receptors

$\begin{array}{lll} & \text { CXCL5 } & 57 \\ & \text { CXCL2 } & 61 \\ & \text { CXCL8 } & 68 \\ & \text { CXCR5 } & 68 \\ & \text { CXCR3 } & 71 \\ & \text { CXCL11 } & 71 \\ & \text { CXCL1 } & 82 \\ & \text { CXCL10 } & 89 \\ \text { a The only gene showing } & \text { CXCL13 } & 89 \\ \text { decreased expression in } & \text { CXCL6 } & 93 \\ \text { tumours } & \end{array}$

defined in the figure. $P<2.4 \mathrm{E}-6$ is the Bonferroni corrected significance level recommended when all genes in a 20818 gene array is tested. Only two genes fall below this level. Fold changes can be found in each shape

subject, and there are as many studies showing no difference or an even better prognosis in young patients as there are studies showing a poor prognosis [24-29, 33]. In this small cohort of 38 patients, we did not see any significant difference in overall survival between young and old patients.

CXC-chemokines has previously been connected to response to treatment, but their roles in cancerogenesis differ between tumour types. We therefore wanted to clarify which CXC-chemokines have a changed expression in tongue tumours and their relation to radiation resistance. The tongue additionally differs morphologically from other tissues in the oral cavity, and it has recently been shown that both normal and malignant tongue tissue are molecularly distinct from other tissues within the region, indicating that collectively analysing all tissues in the oral cavity as done historically could be misleading [34, 35]. In our study, eight CXCchemokine ligands and three receptors were significantly upregulated and one receptor was significantly down-regulated in tongue tumours. Expression of one of the CXC-ligands, CXCL10, was strongly associated to radiation response. Categorising CXCL10 expression into three groups showed that it was especially patients with the highest expression of CXCL10 that respond poorly to radiotherapy.

Table 3 Logistic regression after categorising CXCL10 expression into low, medium and high

\begin{tabular}{llrl}
\hline & $p$ value & OR and 95\% CI \\
\hline CXCL10 expression (high vs low) & 0.01 & 19.2 & $(1.88-196.53)$ \\
CXCL10 expression (high vs medium) & 0.07 & 4.8 & $(0.86-26.79)$
\end{tabular}


CXCL10 has an unclear role in cancer. It is angiostatic and as expected has anti-tumour characteristics [36]. Intratumoral injection of CXCL10 leads to reduced growth and impaired angiogenesis and metastasis in murine adenocarcinoma and studies have shown a synergistic effect against tumours through its immunomodulatory properties in murine models of glioma and melanoma [37-39]. Both CXCL10 and its receptor CXCR3 are on the other hand over-expressed in many tumours and have been connected to poor prognosis and metastasis in a number of cancers, including colon cancer, multiple myeloma, breast cancer and basal cell carcinoma [40-44]. Simultaneous expressions of CXCL10 and CXCR3 in breast cancer cell lines additionally lead to CXCL10dependent proliferation of CXCR3-positive cells and treatments using CXCR3 antagonists, and ligand-neutralizing antibodies inhibit metastasis in melanoma and breast cancer in mice [45-47]. Explanations to the dual role of CXCL10 as both a tumour inhibitor and a tumour promoter can be many; the receptor CXCR3, for example, exists in three isoforms (CXCR3-A CXCR3-B and CXCR3-alt) with different outcomes upon activation, and the balance between the three could be of importance; structural properties of CXCL10 are thought to be significant for in vivo activity, and the effect of CXCL10 signalling is suggested to vary depending on whether the microenvironment or the tumour cells express the receptor $[36,48,49]$. Treatments targeting CXCL10 therefore have to be used with care today, and it is important to fully understand the role of CXCL10 in individual tumour types and subgroups of tumours.

CXCR1 is the only chemokine in our study showing significant down-regulation. CXCR1 together with CXCR2 represent the two angiogenic receptors even though CXCR2 is considered the major angiogenic receptor in humans [50]. The two ligands for CXCR1, CXCL6 and CXCL8, which also activate CXCR2, are both up-regulated, indicating that a shift towards activation of CXCR2 could be of importance for tongue carcinoma. Antibody-based inhibition of CXCR2 in pancreatic cancer models has previously been shown to block angiogenesis with an accompanying reduction in tumour growth, and a recent study of CXCR2 and oral cancer showed antagonist inhibition of CXCR2 to decrease tumour cell viability [51-53].

The main limitation of this study is the restricted number of available samples. We included all tongue tumour patients treated at Norrlands University Hospital between 1998 and 2010 that had gone through preoperative radiotherapy and surgery and for which there were an available tumour sample from diagnosis. Still, only 12 patients with a non-cPR were available and confirmation of our result in an independent dataset will be important. The arrays from which we retrieve the expression data contains probes for 20818 genes. If we were to test them all, the very stringent and commonly used Bonferroni correction would be applied, and the significance level would be set to $p<2.4 \mathrm{E}-6$. This would result in only CXCL1 and CXCL10 being considered significantly upregulated (Fig. 2). The Bonferroni correction ensures that the majority of the identified genes in large-scale experiments are true positives but simultaneously reduces the sensitivity of the analysis. The present study was, even though utilizing microarray data, based on a prior hypothesis and investigating a limited number of genes, and we therefore did not take multiple testing into consideration.

In conclusion, we have comprehensively characterized the expression of the CXC-chemokine ligands and their receptors in tongue tumours. We have correlated their expression to pathological response to radiotherapy and found that especially a group of patients with highly increased expression of CXCL10 is associated with non-complete response, indicating a role for this gene in resistance to radiotherapy. Additionally, we have confirmed the importance of cPR for overall survival of tongue carcinoma patients. Taken together, our data identify high-level CXCL10 expression as a predictive biomarker for poor response to radiotherapy in tongue cancers. These patients may therefore benefit from alternative treatments, possibly involving specific targeting of CXCL10.

Acknowledgments This study was supported by grants from the Cancer Research Foundation in Northern Sweden, Lion's Cancer Research Foundation, Umea University, the Swedish Cancer Society contract number 130716 and Vasterbotten County Council.

Conflicts of interest The authors declare that they have no conflict of interest

Open Access This article is distributed under the terms of the Creative Commons Attribution License which permits any use, distribution, and reproduction in any medium, provided the original author(s) and the source are credited.

\section{References}

1. Jemal A, Bray F, Center MM, Ferlay J, Ward E, Forman D. Global cancer statistics. CA Cancer J Clin. 2011;61(2):69-90.

2. Sahu N, Grandis JR. New advances in molecular approaches to head and neck squamous cell carcinoma. Anticancer Drugs. 2011;22(7):656-64.

3. Sano D, Myers JN. Metastasis of squamous cell carcinoma of the oral tongue. Cancer Metastasis Rev. 2007;26(3-4):645-62.

4. Grandi C, Alloisio M, Moglia D, Podrecca S, Sala L, Salvatori P, et al. Prognostic significance of lymphatic spread in head and neck carcinomas: therapeutic implications. Head Neck Surg. 1985;8(2):67-73.

5. Kalnins IK, Leonard AG, Sako K, Razack MS, Shedd DP. Correlation between prognosis and degree of lymph node involvement in carcinoma of the oral cavity. Am j surg. 1977;134(4):450-4.

6. Dinshaw KA, Agarwal JP, Ghosh-Laskar S, Gupta T, Shrivastava SK. Radical radiotherapy in head and neck squamous cell carcinoma: an analysis of prognostic and therapeutic factors. Clin Oncol (R Coll Radiol). 2006;18(5):383-9.

7. Moeller BJ, Richardson RA, Dewhirst MW. Hypoxia and radiotherapy: opportunities for improved outcomes in cancer treatment. Cancer Metastasis Rev. 2007;26(2):241-8. 
8. Shintani S, Mihara M, Li C, Nakahara Y, Hino S, Nakashiro K, et al. Up-regulation of DNA-dependent protein kinase correlates with radiation resistance in oral squamous cell carcinoma. Cancer Sci. 2003;94(10):894-900.

9. Silva P, Homer JJ, Slevin NJ, Musgrove BT, Sloan P, Price P, et al. Clinical and biological factors affecting response to radiotherapy in patients with head and neck cancer: a review. Clin Otolaryngol. 2007;32(5):337-45.

10. Allen CT, Judd NP, Bui JD, Uppaluri R. The clinical implications of antitumor immunity in head and neck cancer. Laryngoscope. 2012;122(1):144-57.

11. Tong CC, Kao J, Sikora AG. Recognizing and reversing the immunosuppressive tumor microenvironment of head and neck cancer. Immunol Res. 2012;54(1-3):266-74.

12. Yeudall WA, Miyazaki H. Chemokines and squamous cancer of the head and neck: targets for therapeutic intervention? Expert Rev Anticancer Ther. 2007;7(3):351-60.

13. Matsumura S, Wang B, Kawashima N, Braunstein S, Badura M, Cameron TO, et al. Radiation-induced CXCL16 release by breast cancer cells attracts effector T cells. J Immunol. 2008;181(5):3099-107.

14. Muller A, Sonkoly E, Eulert C, Gerber PA, Kubitza R, Schirlau K, et al. Chemokine receptors in head and neck cancer: association with metastatic spread and regulation during chemotherapy. Inte J Cancer. 2006;118(9):2147-57.

15. Wang J, Seethala RR, Zhang Q, Gooding W, van Waes C, Hasegawa $\mathrm{H}$, et al. Autocrine and paracrine chemokine receptor 7 activation in head and neck cancer: implications for therapy. J Natl Cancer Inst. 2008;100(7):502-12.

16. Cojoc M, Peitzsch C, Trautmann F, Polishchuk L, Telegeev GD, Dubrovska A. Emerging targets in cancer management: role of the CXCL12/CXCR4 axis. Oncol Targets Ther. 2013;6:1347-61.

17. Hutchings CJ, Koglin M, Marshall FH. Therapeutic antibodies directed at $\mathrm{G}$ protein-coupled receptors. MAbs. 2010;2(6):594-606.

18. Zhu A, Zhan W, Liang Z, Yoon Y, Yang H, Grossniklaus HE, et al. Dipyrimidine amines: a novel class of chemokine receptor type 4 antagonists with high specificity. J Med Chem. 2010;53(24):8556-68.

19. Wolff HA, Rolke D, Rave-Frank M, Schirmer M, Eicheler W, Doerfler A, et al. Analysis of chemokine and chemokine receptor expression in squamous cell carcinoma of the head and neck (SCCH N) cell lines. Radiat Environ Biophys. 2011;50(1):145-54.

20. Beskow C, Agren-Cronqvist AK, Granath F, Frankendal B, Lewensohn R. Pathologic complete remission after preoperative intracavitary radiotherapy of cervical cancer stage $\mathrm{Ib}$ and IIa is a strong prognostic factor for long-term survival: analysis of the Radiumhemmet data 1989-1991. Int J Gynecol Cancer. 2002;12(2):158-70.

21. Friesland S, Fernberg JO, Lundell G, Munck-Wikland E, Strander H, Lewensohn R. Prognostic impact of complete remission after preoperative irradiation of tonsillar carcinoma: a retrospective analysis of the Radiumhemmet data, 1980-1995. Int J Radiat Oncol Biol Phys. 1999;45(5):1259-66.

22. Montagna E, Bagnardi V, Rotmensz N, Viale G, Pruneri G, Veronesi $\mathrm{P}$, et al. Pathological complete response after preoperative systemic therapy and outcome: relevance of clinical and biologic baseline features. Breast Cancer Res Treat. 2010;124(3):689-99.

23. Lundqvist L, Stenlund H, Laurell G, Nylander K. The importance of stromal inflammation in squamous cell carcinoma of the tongue. $\mathrm{J}$ Oral Pathol Med. 2012;41(5):379-83.

24. Annertz K, Anderson H, Biorklund A, Moller T, Kantola S, Mork J, et al. Incidence and survival of squamous cell carcinoma of the tongue in Scandinavia, with special reference to young adults. Int $\mathrm{J}$ Cancer. 2002;101(1):95-9.

25. Atula S, Grenman R, Laippala P, Syrjanen S. Cancer of the tongue in patients younger than 40 years. A distinct entity? Arch Otolaryngol Head Neck Surg. 1996;122(12):1313-9.

26. Garavello W, Spreafico R, Gaini RM. Oral tongue cancer in young patients: a matched analysis. Oral Oncol. 2007;43(9):894-7.
27. Sarkaria JN, Harari PM. Oral tongue cancer in young adults less than 40 years of age: rationale for aggressive therapy. Head Neck. 1994;16(2):107-11.

28. Schantz SP, Yu GP. Head and neck cancer incidence trends in young Americans, 1973-1997, with a special analysis for tongue cancer. Arch Otolaryngol Head Neck Surg. 2002;128(3):268-74.

29. Pytynia KB, Grant JR, Etzel CJ, Roberts D, Wei Q, Sturgis EM. Matched analysis of survival in patients with squamous cell carcinoma of the head and neck diagnosed before and after 40 years of age. Arch Otolaryngol Head Neck Surg. 2004;130(7):869-73.

30. Rentoft M, Coates PJ, Laurell G, Nylander K. Transcriptional profiling of formalin fixed paraffin embedded tissue: pitfalls and recommendations for identifying biologically relevant changes. PLoS ONE. 2012;7(4):e35276.

31. Calmon MF, Rodrigues RV, Kaneto CM, Moura RP, Silva SD, Mota LD, et al. Epigenetic silencing of CRABP2 and MX1 in head and neck tumors. Neoplasia (New York, NY). 2009;11(12):1329-39.

32. Rentoft M, Hultin S, Coates PJ, Laurell G, Nylander K. Tubulin alpha- 6 chain is a stably expressed reference gene in archival samples of normal oral tissue and oral squamous cell carcinoma. Exp Ther Med. 2010;1(3):419-23.

33. Schantz SP, Hsu TC, Ainslie N, Moser RP. Young adults with head and neck cancer express increased susceptibility to mutagen-induced chromosome damage. JAMA. 1989;262(23):3313-5.

34. Boldrup L, Coates PJ, Laurell G, Nylander K. Differences in p63 expression in SCCHN tumours of different sub-sites within the oral cavity. Oral Oncol. 2011;47(9):861-5.

35. Ziober AF, Patel KR, Alawi F, Gimotty P, Weber RS, Feldman MM, et al. Identification of a gene signature for rapid screening of oral squamous cell carcinoma. Clin Cancer Res. 2006;12(20 Pt 1):5960 71.

36. Liu M, Guo S, Stiles JK. The emerging role of CXCL10 in cancer (review). Oncol Lett. 2011;2(4):583-9.

37. Fujita M, Zhu X, Ueda R, Sasaki K, Kohanbash G, Kastenhuber ER, et al. Effective immunotherapy against murine gliomas using type 1 polarizing dendritic cells - significant roles of CXCL10. Cancer Res. 2009;69(4):1587-95.

38. Struyf S, Burdick MD, Peeters E, Van den Broeck K, Dillen C, Proost $\mathrm{P}$, et al. Platelet factor-4 variant chemokine CXCL4L1 inhibits melanoma and lung carcinoma growth and metastasis by preventing angiogenesis. Cancer Res. 2007;67(12):5940-8.

39. Lu XL, Jiang XB, Liu RE, Zhang SM. The enhanced anti-angiogenic and antitumor effects of combining flk1-based DNA vaccine and IP10. Vaccine. 2008;26(42):5352-7.

40. Zipin-Roitman A, Meshel T, Sagi-Assif O, Shalmon B, Avivi C, Pfeffer RM, et al. CXCL10 promotes invasion-related properties in human colorectal carcinoma cells. Cancer Res. 2007;67(7):3396405 .

41. Pellegrino A, Antonaci F, Russo F, Merchionne F, Ribatti D, Vacca A, et al. CXCR3-binding chemokines in multiple myeloma. Cancer Lett. 2004;207(2):221-7.

42. Kawada K, Hosogi H, Sonoshita M, Sakashita H, Manabe T, Shimahara $\mathrm{Y}$, et al. Chemokine receptor CXCR3 promotes colon cancer metastasis to lymph nodes. Oncogene. 2007;26(32):4679-88.

43. Lo BK, Yu M, Zloty D, Cowan B, Shapiro J, McElwee KJ. CXCR3/ ligands are significantly involved in the tumorigenesis of basal cell carcinomas. Am J Pathol. 2010;176(5):2435-46.

44. Mulligan AM, Raitman I, Feeley L, Pinnaduwage D, Nguyen LT, O'Malley FP, et al. Tumoral lymphocytic infiltration and expression of the chemokine CXCL10 in breast cancers from the Ontario Familial Breast Cancer Registry. Clin Cancer Res. 2013;19(2):33646.

45. Goldberg-Bittman L, Neumark E, Sagi-Assif O, Azenshtein E, Meshel T, Witz IP, et al. The expression of the chemokine receptor CXCR3 and its ligand, CXCL10, in human breast adenocarcinoma cell lines. Immunol Lett. 2004;92(1-2):171-8. 
46. Kawada K, Sonoshita M, Sakashita H, Takabayashi A, Yamaoka Y, Manabe T, et al. Pivotal role of CXCR3 in melanoma cell metastasis to lymph nodes. Cancer Res. 2004;64(11):4010-7.

47. Walser TC, Rifat S, Ma X, Kundu N, Ward C, Goloubeva O, et al. Antagonism of CXCR3 inhibits lung metastasis in a murine model of metastatic breast cancer. Cancer Res. 2006;66(15):7701-7.

48. Vandercappellen J, Van Damme J, Struyf S. The role of CXC chemokines and their receptors in cancer. Cancer Lett. 2008;267(2): 226-44.

49. Wu Q, Dhir R, Wells A. Altered CXCR3 isoform expression regulates prostate cancer cell migration and invasion. Mol Cancer. 2012;11(3).

50. Addison CL, Daniel TO, Burdick MD, Liu H, Ehlert JE, Xue YY, et al. The CXC chemokine receptor 2, CXCR2, is the putative receptor for ELR $+\mathrm{CXC}$ chemokine-induced angiogenic activity. J Immunol. 2000;165(9):5269-77.

51. Wente MN, Keane MP, Burdick MD, Friess H, Buchler MW, Ceyhan $\mathrm{GO}$, et al. Blockade of the chemokine receptor CXCR2 inhibits pancreatic cancer cell-induced angiogenesis. Cancer Lett. 2006;241(2):221-7.

52. Matsuo Y, Raimondo M, Woodward TA, Wallace MB, Gill KR, Tong Z, et al. CXC-chemokine/CXCR2 biological axis promotes angiogenesis in vitro and in vivo in pancreatic cancer. Int $\mathrm{J}$ Cancer. 2009;125(5):1027-37.

53. Romanini J, Mielcke TR, Leal PC, Figueiredo CP, Calixto JB, Morrone FB, et al. The role of CXCR2 chemokine receptors in the oral squamous cell carcinoma. Investig New Drugs. 2012;30(4): 1371-8. 